\title{
IMPROVING READING IN CHILDREN WITH GERMAN AS A FIRST OR SECOND
}

\section{LANGUAGE.}

Susanne Schwab, Susanne Seifert* and Barbara Gasteiger-Klicpera

*Corresponding Author

Department of Educational Science, Inclusive Education Unit, University of Graz, Graz, Austria

(Received 2 July 2013; accepted 26 September 2013)

DOI: $10.1080 / 09669760.2014 .909308$ 
Abstract

The study Improving Language And Reading Skills (LARS) in children with German as a first or second language evaluates a newly developed differentiating programme for reading in terms of its effects on the reading and language ability of second graders with German as a first or second language. The participant group consisted of 105 children. 55 children belonged to the group that received the programme (LARS-group) and 50 children received traditional instruction (TI-group). The reading, spelling and language ability of each participating child were assessed before and after the programme period. The children of the LARS-group were supported over three months in terms of reading texts and completing the corresponding tasks. The texts and the tasks were adapted to the students' ability levels (three different ability levels: above average, average and below average level in reading). The results indicate that the learning outcomes for children in the LARS-classes were significantly higher for reading fluency and comprehension but no effect was observed for language and spelling. The results suggest that the LARS programme was equally effective for children with German as a first or second language.

Keywords: evaluation; reading programme; reading comprehension; reading fluency; German as a second language 
In recent years, research in the field of literacy development has revealed a relationship between language skills such as lexis, semantics and grammar and the acquisition of reading skills - phonological recoding as well as reading comprehension - in the first years of schooling (Snowling and Hulme 2005; Oakhill and Cain 2011; Perfetti, Landi, and Oakhill 2005).

Given the important role that language abilities play in reading acquisition, some groups of children may be at a greater risk of developing learning difficulties in reading and spelling than others. Children with specific language impairment or communication disorders, for instance, often experience literacy problems (Bishop and Snowling 2004; Catts et al. 2002; Ricketts 2011). Furthermore, children whose first language (L1) is not the language of instruction in school (Burgoyne, Whiteley, and Hutchinson 2011) and children from socially disadvantaged families (Potter 2007) may experience particular problems with literacy development and later school attainment. Consequently, support for migrant children is seen as an essential factor in ensuring educational success (Baumert, Stanat, and Waterman 2006).

The Austrian and German educational systems so far have not been very successful in reducing social disparities or in providing equal opportunities for children from diverse backgrounds prior to their start to school. A number of studies have shown that difficulties in reading emerge at an early stage and affect early literacy development (e.g. Ding, Richardson, and Schnell 2013; Klicpera and Gasteiger-Klicpera 1993; Scarborough and Parker 2003; Stanovich 1986). These studies also suggest that early intervention offers the most effective means of remediating later difficulties by identifying at risk children and by providing individual learning support (e.g. Gasteiger-Klicpera and Fischer 2008; Helf and Cooke 2011; Hurry and Sylva 2007; Rose 2006; Swanson 1999; Torgesen 2005).

Meta-analyses show that reading intervention programmes in general are very effective (e.g. Souvignier and Antoniou 2007; Berkeley, Scruggs, and Mastropieri 2009; Ise, 
Engel, and Schulte-Körne 2012; Slavin et al. 2009). However, different factors influence the effectiveness of such programmes. Souvignier and Antoniou (2007) claimed that the intervention's setting (single intervention, small group intervention, parenting instruction, school class), the group of children being supported (e.g. only children with difficulties in reading or children with German as second language) and the intensity of the intervention (numbers of remedial lessons, number of lessons per week etc.) determine the effectiveness of the programme. Berkeley et al. (2009) showed that interventions implemented by researchers are more effective than those implemented by teachers. Slavin et al. (2009) investigated the effects of reading programmes on classroom practice. They showed that programmes which changed classroom practice through special focus on teacher training and development achieved better effects than those programs that aimed at changing whole reading curricula. Similar findings were revealed for intervention programmes for dyslexic children in Germanspeaking countries. Ise, Engel and Schulte-Körne (2012) noted that symptom-specific intervention programmes proved to be more effective than function and awareness trainings. The intensity of intervention, as well as the person implementing the intervention (teacher vs. researcher), were also found to affect the results. In contrast to Berkeley et al. (2009), Ise, Engel and Schulte-Körne (2012) revealed that interventions implemented by teachers obtained higher effects than those implemented by researchers.

Concerning the acquisition of literacy, numerous programmes have been initiated especially in English-speaking countries. Evidence from the impact of these programmes suggests that an emphasis on phonics during reading instruction in the first years of literacy education benefits a child's reading acquisition (Ehri et al. 2001; Rose 2006). For instance, the Cumbria Reading Intervention programme (e.g. Hatcher, Hulme, and Ellis 1994) uses phonological training in combination with reading. This programme seems to be very effective in helping English-speaking children develop their reading skills. Similarly, the SFA programme (Success for All; Slavin 1996) uses phonics and combines them with cooperative 
learning. This was proven to be quite successful for struggling readers (Joliffe 2006; Slavin et al. 2009). In addition, a number of intervention programmes focus on teaching reading strategies to enhance students' reading comprehension skills. For example, the reciprocal teaching programme (Brown and Palincsar 1982) is widely known as a programme that improves children's text comprehension through explicit strategy instruction. The CORI programme (Concept Oriented Reading Instruction; Guthrie and Cox 1998), which adds motivational support to strategy instruction, has also proven successful (Guthrie, Wigfield, and Perencevich 2004). However, this programme is targeted at older children rather than younger primary school children (see also Hagaman, Casey, and Reid 2012). The paraphrasestrategy RAP (Read, Ask myself and Put it in own words; Schumaker, Denton, and Deshler 1984) is another intervention which appears effective in supporting children's literacy development (e.g. Ellis and Graves 1990).

Several English programmes, or at least parts of them, have been adapted for use in German speaking countries. For example, the Leseprofi-Training for third-graders (MunserKiefer and Kirschhock 2009) integrates aspects of the CORI programme (Guthrie, Wigfield, and Perencevich 2004) and the paraphrase-strategy used in the RAP (Schumaker, Denton, and Deshler 1984). According to Munser-Kiefer and Kirschhock (2009), paired reading with the Leseprofi-Training in primary school leads to better reading comprehension than small groups reading. A possible reason why paired reading seems to be more successful could be the increased practice time.

Only a limited number of theoretically sound and evidence-based reading programmes for classroom use has been evaluated so far (Gasteiger-Klicpera and Fischer 2008). Further, the number of programmes taking children of German as a second language (children with L2 German) into consideration is small as well.

A specific problem of children with L2 German is lack of vocabulary to comprehend texts. As shown in many studies, implementing vocabulary in reading programmes seems to 
be one effective method in order to enhance reading comprehension (Souvignier and Antoniou 2007; Carlson et al. 2013; Cassidy and Cassidy 2006; Rupley, Logan, and Nichols 1999). Especially for second language learners, reading instruction should include vocabulary work. Literacy enhancement programmes which combine multiple practices are more successful than single strand programmes (Ferguson et al. 2011; Stobie et al. 2004).

\section{Purpose and research questions}

The purpose of the study is to evaluate the effects of a theoretically sound reading and language enhancement programme. An intensive, systematic reading programme adapted to three different reading levels (above average, average and below average level in reading), was implemented by classroom teachers into regular lessons. The program focused especially on those students who showed low literacy and/or linguistic skills in German. Since the programme was designed to be used in whole class settings, average and proficient readers could also profit due to the adaptation of texts and reading comprehension activities to the different reading levels. In order to evaluate the programme's effectiveness, second grade children who received instruction with the programme needed to be compared to second grade students who received traditional instruction. Aspects of comparison were reading fluency, reading comprehension, spelling and linguistic competencies (lexicon, syntax, phonological awareness).

Earlier intervention studies have already shown that the reading abilities of children with L2 German had shown greater improvement when compared to children with German as L1 after specific reading support (Fischer and Gasteiger-Klicpera 2011). Therefore, it needs to be investigated if these results hold true for the LARS programme as well. 


\section{Methods}

The study was conducted in a quasi-experimental pre-post-test-design with a comparison group. At the beginning of November 2011 (test time 1), children of six second grade classes of two different primary schools were tested with parental permission. Both schools had a similar catchment area. This assured that socioeconomic and cultural background of parents and children were comparable. Approximately $70 \%$ of the pupils were children with L2 German.

From March to June 2012, the whole-class reading programme LARS was provided to three classrooms (LARS-group). The other three classes - constituting the comparison group received traditional instruction (TI-group). At the end of June 2012 (test time 2) the reading and language skills of all children were assessed again.

As the children were guaranteed anonymity to ensure protection in ethical ways (Mortari and Harcourt 2012), all data were coded.

\section{Participant Group}

In the course of the evaluation-study, all children of the second grade classes of two primary schools were examined. One of the schools was randomly assigned to participate as the school receiving the LARS-programme (LARS-school), whereas the other school was assigned to serve as a comparison group (TI-school) to assure there was no transfer between intervention and comparison group. Twelve children ( 2 of the LARS-school, 10 of the TI school), who received a percentile rank below 5 in reading fluency (word-decoding of the SLRT II; Moll and Landerl 2010), were excluded from the analyses. Due to their poor reading skills they received another form of support (single and small group intervention) (see Schwab, Seifert, and Gasteiger-Klicpera 2013). Thus, in total 105 children (58 boys, 47 girls) participated in the study. On average, the children were 7.95 years old $(S D=0.49)$. Less than one third of the participants (29\%) had German as L1, the remaining 71\% had German as L2. 
Overall, 18 different languages were spoken. 55 children $(58.2 \%$ boys, $41.8 \%$ girls; average age: 8.01 years $(S D=0.56) ; 69.1 \%$ German as L2) of three school classes received the programme (LARS). 50 children $(52 \%$ boys, $48 \%$ girls; average age: 7.89 years $(S D=0.39)$; $74 \%$ German as L2) of three school classes belonged to the TI-group.

The age difference was not significant, $t(96.39)=-1.2, p=$ n.s. The gender distribution, $\chi^{2}(1$, $n=105)=0.41, p=$ n.s., and also the distribution of children with German as L2, $\chi^{2}(1, n$ $=105)=0.31, p=$ n.s., were similar in both groups. The participant group was therefore well balanced.

\section{Description of the reading programme}

Teachers worked twice a week for 50 minutes with the materials of the LARS programme for three months (approximately 30 programme lessons). The programme was implemented into regular lessons. Therefore, the content of the reading texts reflected the main subjects of instruction in the elementary grades. This ensured that the texts and the vocabulary were relevant for the children.

The reading programme LARS (see also Gasteiger-Klicpera and Fischer 2008; Schwab and Oswald 2011) comes in three different skill levels. In order to group the pupils accordingly, a specific assessment of the different components of reading abilities (phonological recoding, lexical reading and reading comprehension) was needed for each child. Based on the results of the formal assessment, each child was assigned one of the three ability levels. These ability levels ensured differentiated work on the same topic so that joint learning on the same subject became possible (see also Feyerer and Prammer 2003).

Since the programme combines the enhancement of reading with vocabulary development, the material was sub-divided into thematic units. Vocabulary and topics were introduced in lessons prior to working with the texts. Afterwards, students worked 
independently with a text corresponding to their individual reading skill level and fitting the introduced topic. The texts, either informative or narrative, varied depending on the ability levels in three components: (1) in complexity of sentences, (2) in length of the sentences and (3) in the complexity and length of the text itself. Furthermore, there were variations concerning the complexity and the amount of tasks to be completed by the children while and after reading. After the compulsory reading of the text as well as completing the respective tasks, opportunities for self-regulated and independent reading of texts and books were provided.

For the introduction of the different thematic units, appropriate vocabulary material (hidden object pictures, anchor-words with pictures) was provided. This vocabulary was considered thematically relevant and was controlled for grammatical, prosodic and orthographic aspects as well as for word frequency. These words frequently appeared in the texts and tasks. Words that occur in the language test WWT (Glück 2007) were not used in the programme in order to avoid training effects.

The implementation was conducted by the classroom teacher, working together with a project member, whereby the teacher had the leading role.

\section{Instruments}

The reading part of the Salzburger reading and spelling test (SLRT II: Moll and Landerl 2010) was used to measure the acquisition of literacy competences. The SLRT II is an individual reading test, which assesses reading fluency of words and pseudo-words. It allows a separate diagnosis of phonological recoding and lexical reading. Reading comprehension was tested with a reading comprehension test for first to sixth graders (Elfe 16: Lenhard and Schneider 2006). The Elfe 1-6 evaluates reading comprehension on the word-, sentence- and text-level. Spelling skills were tested with the Hamburger Schreibprobe (HSP 
1-9: May 2002).Vocabulary (active and passive) was tested with the short form of the vocabulary- and word finding-test for 6 to 10 year olds (WWT 6-10: Glück 2007). Grammar of expressive language, expressive language analogies and phonological decoding (repeating sentences orally) were measured with the subtests of the Potsdam-Illinois test for psycholinguistic abilities (P-ITPA: Esser et al. 2010). Information about the children's first language was obtained from the teachers.

\section{Statistical analysis}

To analyse the effects on reading and linguistic skills two multivariate variance analyses were calculated. The type of enrolment (LARS-group vs. TI-group) served as independent variable. The achievement of the children was assessed (word-reading-fluency, pseudo-word-reading fluency, active vocabulary, grammar, phonological awareness). These dependent variables were used as raw score differences ( $\mathrm{t} 2$ minus $\mathrm{t} 1$ ) for the analyses. Percentile rank differences ( $\mathrm{t} 2$ minus $\mathrm{t} 1$ ) were used for the calculation of reading comprehension and spelling abilities.

Regarding the baseline results (first testing time) of the LARS-group and the TI-group, no significant differences concerning general intelligence, linguistic and literacy skills could be found. Only the subtest 'expressive language analogies', $t(90.234)=2.41, p<.05$ revealed differences. Therefore, this subtest was excluded from further analyses.

Concerning the baseline results of children with German as L1 and children with German as L2, some differences could be detected in reading comprehension, $t(103)=3.26, p<.01$, in the active, $t(103)=6.76, p<.01$, and passive vocabulary, $t(84.508)=5.77, p<.01$, and also in grammar, $t(92.698)=4.75, p<.01$, analogies, $t(103)=3.78, p<.01$, and phonological decoding, $t(103)=4.39, p<.01$. In all of these tests children with German as L1 performed 
better than those with German as L2. In the other tests, no differences were found between those two groups.

\section{Results}

\section{Effects of the programme on reading skills}

The multivariate variance analysis shows a significant main effect for the type of enrolment (dependent variables: word decoding, pseudo-word decoding, reading comprehension (percentile rank (PR)). Children of the LARS-classes showed significant higher increases than children of the TI-classes, $F(3,99)=25.42, p<.01, \eta^{2}=.44$. In both, word-reading and pseudo-word-reading, children participating in the LARS programme achieved higher performance gains than those who did not receive any intervention (see Table 1). The same effect could also be observed in reading comprehension. The effective strengths showed medium to strong effect sizes $\left(\eta^{2}=.14\right.$ to .42 ; see Table 1$)$ in reading fluency of words and pseudo-words as well as in reading comprehension.

Table 1

Furthermore, the analyses showed no main effect for mother tongue (German as L1 vs. L2) regarding reading gains (dependent variables: word decoding, pseudo-word decoding, reading comprehension (PR)). Children with German as L1 showed the same gains as children with German as L2, $F(3,99)=0.94$, n.s., $\eta^{2}=.03$. 


\section{Differential effects of the programme on reading skills}

In order to answer the question, whether children with German as L1 and as L2 profit equally from the programme or not, the interactions between the type of enrolment and mother tongue (German as L1 vs. L2) were analysed. The results showed that besides the above mentioned main effect, there were no interactions, $F(3,99)=0.95$, n.s., $\eta^{2}=.03$. Thus, the subtests word decoding, $F(1,99)=0.05$, n.s., $\eta^{2}=.00$, pseudo-word decoding, $F(1,99)=$ 1.13 , n.s., $\eta^{2}=.01$, and reading comprehension, $F(1,99)=0.02$, n.s., $\eta^{2}=.00$, did not show any interactions (see Figure 1).

Figure 1

\section{Effects of the programme on linguistic and spelling skills}

The multivariate variance analysis (dependent variables: spelling (PR), active vocabulary, passive vocabulary, grammar, phonological decoding) did not show any significant main-effect for the type of enrolment, $F(5,97)=0.29$, n.s., $\eta^{2}=.02$. Children of the LARS-classes showed the same performance in all subtests as the children of the TIclasses (see Table 2). In spelling, vocabulary (both active and passive), grammar and phonological decoding skills, no differences were observed between the LARS- and the TIgroup.

Table 2

Independently from the type of enrolment and therefore independent from the programme, the analysis showed a main effect for mother tongue (German as L1 vs. L2; dependent variables: spelling (PR), active vocabulary, passive vocabulary, grammar, 
phonological decoding). Children with German as L2 showed higher gains in language abilities than children with German as L1, $F(5,97)=2.82, p<.05, \eta^{2}=.13$.

\section{Differential effects of the programme on linguistic and spelling skills}

Although variance analysis could not show any overall effects of the programme on linguistic and spelling skills, the interactions between type of enrolment and mother tongue (German as L1 vs. L2) were analysed. The results show that there were no interactions, $F(5$, $97)=0.35$, n.s., $\eta^{2}=.02$ ). Nor with differentiated consideration of the subtests, any differential effects could be shown (see Figure 2).

Figure 2

\section{Discussion}

The aim of the current study was to prove the effects of a combined language and reading programme concerning reading skills as well as spelling and linguistic competencies. By comparing with the group receiving traditional instruction, it could be shown that the LARS programme led to larger increases in reading fluency and in reading comprehension within a short timeframe. Thus, this systematically and differentiating language and reading programme created for children with difficult starting conditions obviously offers them a possibility to develop their reading competencies, even more than this was the case in traditional instructional settings. Different performance gains between the LARS- and the TIgroup in linguistic and spelling skills could not be assessed.

In spelling, vocabulary (active and passive), grammar and phonological decoding tests, the LARS-group did not show larger increases than the TI-group. These findings have to be discussed especially for vocabulary, as within the programme a lot of vocabulary work was 
conducted, although the emphasis was on reading. Probably the vocabulary contained special words that were not relevant for the children's daily linguistic routine. Certainly, the results of the word reading comprehension subtest (ELFE 1-6: Lenhard and Schneider 2006) indicate that the children might have enlarged their vocabulary, since they were able to match more words to the pictures than the comparison group. However, the method of learning vocabulary through several opportunities of encountering the word in question in different contexts while reading is known to improve vocabulary sustainably (Bolger et al. 2008; Sternberg and Powell 1983).This has positively been investigated for first and second language acquisition (Nation 2001). Therefore, it could be argued that the children within this study did encounter the words in fewer occasions than it would be useful for an adequate acquisition. MestresMissé et al. (2008) found out that it takes three encounters in different written contexts in order to learn the meaning of a new word. In our material, it was not always possible to let the vocabulary occur that often in the texts. However, specific introduction of the vocabulary for each thematic unit was offered. Perhaps, this was not enough. It might be helpful to enrich the programme by methods of active learning in order to ensure the learning effect (Stephen, Ellis, and Martlew 2010), e.g. vocabulary games, or fostering the vocabulary of children with German as L2 also in their L1, as the stimulation of L1 is known to increase vocabulary competencies in L2 (Yazici, Genç İlter, and Glover 2010). However, the trained vocabulary was not tested. It is likely that the children learned the vocabulary offered, but then again did not transfer their knowledge to untrained vocabulary. For further projects, it should be recommended to test for training effects in order to assess if the children attain learning gains in the trained vocabulary.

Both, children with German as L1 and those with German as L2 benefitted from the programme with regard to reading fluency and reading comprehension. Interestingly, regardless of the programme, children with German as L2 gained more insight in the spelling and linguistic abilities than children with German as L1. This fact is shown in the above 
mentioned main effect of mother tongue and can partially be traced back to the children with L2 German's initially worse starting conditions (children with German as L2 showed worse performance on some of the pre-tests compared to children with German as L1). It shows that the gap between the two groups can be reduced. Although in the spelling abilities there were no initial differences between the two groups, children with German as L2 seemed to gain more insight in this ability during the observed period than children with German as L1, both in the LARS- and the TI-group. Obviously, the second grade in general gives children with German as L2 the possibility to extend their knowledge about their second language.

Concerning the current study's interpretation of the results, some restrictions have to be mentioned. The first restriction concerns the choice of the participants. The results are not generalizable for average second grade children as the selected classes (both, LARS- and TIclasses) exhibited a high amount of children with migration background.

Not only is the participating group subject to restrictions in term of being representative, but also the programme itself shows limitations. Which specific part of the programme (e.g. systematically vocabulary work, improvement of reading fluency, fostering different strategies to improve reading comprehension) is responsible for the improvement, is quite hard to assess since the programme comprises different components. Basically, literature indicates that multiple components of reading supported in a reading programme lead to positive effects in the ability of reading (e.g. Guthrie et al. 2004; Wigfield et al. 2008). Perhaps the combination of reading instruction with vocabulary can work as a multicomponent reading programme (Ferguson et al. 2011; Stobie et al. 2004) and therefore contributes to the positive outcomes in reading, although not seen in the vocabulary skills itself. For the current study it is presumed that the high effectiveness of the programme is especially attributable to the quantitatively and qualitatively differentiating material adapted to the initial skills of the children. This enabled the children to work more independently and 
with more individual reading time than they usually get in traditional lessons. Furthermore, the adapted material allowed children to stay motivated as the texts were neither too easy nor too difficult for them but matched exactly with their ability level. However, it can as well be assumed that the permanent presence of a project member had a positive influence on the outcomes of the study. By being present during the programme lessons, inconsistency in the implementation among the classes could be reduced. An additional supporting person is also known to raise children's engagement in the tasks to be solved (Stephen, Ellis, and Martlew 2010). Therefore, the programme's success might be, at least partly, simply due to the presence of the project members.

In conclusion, the programme LARS showed to be an effective method for reading instruction which can easily be implemented into regular lessons. For future work it is recommended to use the newly developed programme for a longer period (Ise, Engel, and Schulte-Körne 2012) and without a project member taking part in every lesson. Instead, the teachers should be trained intensively and continuing teacher training is needed in order to increase the success rate of reading instruction. A reading-expert should support the teacher during the time the programme is implemented (Helf and Cooke 2011; Kretlow and Bartholomew 2010), in order to ensure high quality implementation. Furthermore, we are certain that the children with the lowest reading abilities in the classes (as mentioned before, they were excluded from this study and supported separately, see Schwab, Seifert, and Gasteiger-Klicpera, 2013) would have equally profited from the differentiating classroom programme. Therefore, it is recommended to implement the programme in whole classes fostering literacy competencies of every child in order to enable even children with very difficult starting conditions to participate in class instruction. 


\section{Acknowledgement}

We like to thank the city-education authority, the city hall and the cultural office of the city Graz which supported the current research project financially.

\section{References}

Baumert, P., Stanat, P., and Watermann, R. 2006. Herkunftsbedingte Disparitäten im Bildungswesen: Differenzielle Bildungsprozesse und Probleme der Verteilungsgerechtigkeit. Vertiefende Analysen im Rahmen von PISA 2000 [Sourcerelated Disparities in Education: Differential formation processes and problems of distributive justice. Further analyzes in the context of PISA 2000]. Wiesbaden: VS.

Berkeley, S., Scruggs, T. E., and Mastropieri, M. A. 2009. "Reading Comprehension Instruction for Students With Learning Disabilities, 1995-2006: A Meta-Analysis.” Remedial and Special Education 31: 423-436.

Bishop, D. V. M., and Snowling, M. J. 2004. “Developmental Dyslexia and Specific Language Impairment: Same or Different?” Psychological Bulletin 130 (6): 858-888.

Bolger, D. J., Balass, M., Landen, E., and Perfetti, C. A. 2008. Context Variation and Definitions in Learning the Meanings of Words: An Instance-Based Learning Approach. Discourse Processes 45: 122-159.

Brown, A., and Palincsar, A. 1982. "Inducing Strategic Learning from Texts by Means of Informed, Self-control Training." Topics in Learning and Learning Disabilities 2: 1-17.

Burgoyne, K., Whiteley, H. E., and Hutchinson, J. M. 2011. “The development of comprehension and reading-related skills in children learning English as an additional language and their monolingual, English-speaking peers.” British Journal of Educational Psychology 81 (2): 344-354. 
Carlson, E., Jenkins, F., Li, T., and Brownell, M. 2013. “The Interactions of Vocabulary, Phonemic Awareness, Decoding, and Reading Comprehension." Journal of Educational Research 106 (2): 120-131.

Cassidy, J., and Cassidy, D. 2006. "What's Hot, What's Not for 2006.” Reading Today 23: 1.

Catts, H. W., Fey, M. E., Tomblin, J. B., and Zhang, X. 2002. “A Longitudinal Investigation of Reading Outcomes in Children with Language Impairments.” Journal of Speech, Language, and Hearing Research 45: 1142-1157.

Ding, C., Richardson, L., and Schnell, T. 2013. “A Developmental Perspective on Word Literacy from Kindergarten Through the Second Grade.” Journal of Educational Research 106 (2): 132-145.

Ehri, L. C., Nunes, S. R., Stahl, S. A., and Willows, D. M. 2001. "Systematic Phonics Instruction Helps Students Learn to Read: Evidence from the National Reading Panel's Meta-Analysis." Review of Educational Research 71 (3): 393-447.

Ellis, E. S., and Graves, A. W. 1990. “Teaching Rural Students with Learning Disabilities: A Paraphrasing Strategy to Increase Comprehension of Main Ideas.” Rural Special Education Quarterly 10: 2-10.

Esser, G., Wyschkon, A., Ballaschk, K., and Hänsch, S. 2010. Potsdam-Illinois Test für Psycholinguistische Fähigkeiten - P-ITPA [Potsam-Illinois Test for Psycholinguistic Abilities - P-ITPA]. Göttingen: Hogrefe, Testzentrale.

Feyerer, E., and Prammer, W. 2003. Gemeinsamer Unterricht in der Sekundarstufe I: Anregungen für eine Integrative Praxis [Common Teaching in the Secondary Level 1: Suggestions for Inclusive Practice]. Weinheim; Basel; Berlin: Beltz. Ferguson, N., Currie, L.-A., Paul, M., and Topping, K. 2011. “The Longitudinal Impact of a Comprehensive Literacy Intervention.” Educational Research 53 (3): 237-256. 
Fischer, U., and Gasteiger-Klicpera, B. 2011. Leseförderung durch Wortschatzarbeit: Ergebnisse einer frühen Interventionsstudie zur individuellen Leseförderung [Reading Enhancement through Vocabulary Work: Results of an Early Intervention Study]. In Inklusion in Bildungsinstitutionen - eine Herausforderung an die Heil- und Sonderpädagogik, edited by Lüthe-Klose, B., Langer M.-T., Serke, B., and Urban, M., 272-277. Bad Heilbrunn: Verlag Julius Klinkhardt

Gasteiger-Klicpera, B., and Fischer, U. 2008. "Evidenzbasierte Förderung bei LeseRechtschreibschwierigkeiten [Evidence-based Support for Reading and Spelling Disorders].“ In Sonderpädagogische Förderprogramme im Vergleich, edited by Fingerle, M., and Ellinger, S., 67-84. Stuttgart: Kohlhammer.

Glück, C. W. 2007. Wortschatz- und Wortfindungstest für 6- bis 10-Jährige (WWT 6-10) [Vocabulary and Wordfinding Test for 6 to 10 Year-olds]. München: Elsevier.

Guthrie, J. T., and Cox, K. 1998. Portrait of an Engaging Classroom: Principles of ConceptOriented Reading Instruction for Diverse Students. In Teaching every child every day: learning in diverse schools and classrooms, edited by Harris, K., 77-131. Cambridge, MA: Brookline Books.

Guthrie, J. T., Wigfield, A., and Perencevich, K. C. 2004. Motivating reading comprehension: Concept-Oriented Reading Instruction. Mahwah, NJ: Erlbaum.

Guthrie, J. T., Wigfield, A., Barbosa, P., Perencevich, K. C. , Toboada, A., Davis, M. H., and Tonks, S. 2004. "Increasing Reading Comprehension and Engagement Through Concept-oriented Reading Instruction.” Journal of Educational Psychology 96: 403423.

Hagaman, J. L., Casey, K. J., and Reid, R. 2012. “The Effects of the Paraphrasing Strategy on the Reading Comprehension of Young Students." Remedial and Special Education 33 (2): 110-123. 
Hatcher, P.J., Hulme, C., and Ellis, A.W. 1994. “Ameliorating early reading failure by integrating the teaching of reading and phonological skills: The phonological linkage hypothesis." Child Development 65: 41-57.

Helf, S., and Cooke, N. L. 2011. "Reading Specialist: Key to a Systematic Schoolwide Reading Model.” Preventing School Failure 55 (3): 140-147.

Hurry, J., and Sylva, K. 2007. "Long-term Outcomes of Early Reading Intervention." Journal of Research in Reading 30: 227-258.

Ise, E., Engel, R. R., and Schulte-Körne, G. 2012. "Was Hilft bei der LeseRechtschreibstörung? Ergebnisse einer Metaanalyse zur Wirksamkeit Deutschsprachiger Förderansätze [What Supports Children With Reading and Spelling Disorders? Results of a Meta-Analysis of the Effects of German Support Approaches]“ Kindheit und Entwicklung 21 (2): 122-136.

Joliffe, W. 2006. The National Literacy Strategy: Missing a Crucial Link? A Comparative study of the National Literacy Strategy and Success for All. Education 34 (1): 37-48.

Klicpera, C., and Gasteiger-Klicpera, B. 1993. Lesen und Schreiben - Entwicklung und Schwierigkeiten: Die Wiener Längsschnittuntersuchungen über die Entwicklung, den Verlauf und die Ursachen von Lese- und Schreibschwierigkeiten in der Pflichtschulzeit [Reading and writing - Development and Difficulties: The Vienna Longitudinal Studies on the Development, Progress and Causes of Reading and Writing Difficulties in the Compulsory Education]. Bern: Huber.

Kretlow, A. G., and Bartholomew, C. C. 2010. "Using Coaching to Improve the Fidelity of Evidence-based Practices: A review of Studies.” Teacher Education and Special Education 33 (4): 279-299.

Lenhard, W., and Schneider, W. 2006. Ein Leseverständnistest für Erst- bis Sechstklässler (ELFE 1-6) [Reading Comprehension Test for First to Sixth Graders]. Weinheim: Beltz. 
May, P. 2002. HSP 1-9-Diagnose orthographischer Kompetenz: Zur Erfassung der grundlegenden Rechtschreibstrategien mit der Hamburger Schreibprobe [HSP 1-9Diagnose of Orthographic Competence: Assessment oft he Basic Spelling strategies With the Hamburger Writing Test]. Hamburg: Verlag für pädagogische Medien.

Mestres-Missé, A., Camara, E., Rodriguez-Fornells, A., Rotte, M., and Münte, T. F. 2008. Functional Neuroanatomy of Meaning Acquisition from Context. Journal of Cognitive Neuroscience 20: 2153-2166.

Moll, K., and Landerl, K. 2010. SLRT-II - Verfahren zur Differentialdiagnose von Störungen der Teilkomponenten des Lesens und Schreibens [SLRT II - A Method for the Differential Diagnosis of Disorders of the Subcomponents of Reading and Writing]. Bern: Huber.

Mortari, L., and Harcourt, D. 2012. "Living' ethical dilemmas for researchers when researching with children.” International Journal of Early Years Education 20 (3): 234243.

Munser-Kiefer, M., and Kirschhock, E.-M. 2009. "Entwicklung und Evaluation eines Lesekompetenztrainings: Eine Vorstudie zur Frage nach der geeigneten Sozialform [Development and Evaluation of a Reading Skills Training: A Preliminary Study on the Question of the Appropriate Social Form].” In Europäisierung der Bildung Konsequenzen und Herausforderungen für die Grundschulpädagogik, edited by Röhner, C., Henrichwark, C., and Hopf, M., 166-171. Wiesbaden: VS Verlag.

Nation, I. S. P. 2001. Learning Vocabulary in Another Language. Cambridge, UK: Cambridge University Press.

Oakhill, J. V., and Cain, K. (2011). “The Precursors of Reading Ability in Young Readers: Evidence from a Four-Year Longitudinal Study.” Scientific Studies of Reading 16 (2): 91-121. 
Perfetti, C. A., Landi, N., and Oakhill, J. 2005. The Acquisition of Reading Comprehension Skill. In The Science of Reading, edited by Snowling, M. J., and Hulme, C., 227-247. Malden: Blackwell.

Potter, C. 2007. „Developments in UK early years policy and practice: can they improve outcomes for disadvantaged children?" Journal of Early Years Education 15 (2): 171180.

Ricketts, J. 2011. "Research review: reading comprehension in developmental disorders of language and communication." Journal of Child Psychology and Psychiatry 52 (11): 1111-1123.

Rose, J. 2006. Independent review of the teaching of early reading: Final report. London: Department for Education and Skills.

Rupley, W. H., Logan, J. W., and Nichols, W. D. 1999. "Vocabulary Instruction in a Balanced Reading Program.” The Reading Teacher 52: 336-346.

Scarborough, H. S., and Parker, J. L. 2003. "Matthew Effects in Children with Learning Disabilities: Development of Reading, IQ and Psychosocial Problems from Grade 2 to Grade 8." Annals of Dyslexia 53: 47-71.

Schumaker, J. B., Denton, P. H., and Deshler, D. D. 1984. The Paraphrasing Strategy. Lawrence: University of Kansas.

Schwab, S., and Oswald. S. 2011. Improving Language And Reading Skills in Children with German as a First or Second Language - LARS. In Erstausgabe IV, edited by KarlFranzens-Universität Graz, 137-147. Graz: Uni-Press Graz.

Schwab, S., Seifert, S., and Gasteiger-Klicpera, B. 2013. Reading intervention in secondgrade children with poor reading abilities. Procedia - Social and Behavioral Sciences 106: $2205-2216$.

Slavin, R. E. 1996. Education for all. The Netherlands: Swets \& Zeitlinger, B. V. Lisse. 
Slavin, R. E., Lake, C., Chambers, B., Cheung, A. and Davis, S. 2009. "Effective Reading Programs for the Elementary Grades: Best-evidence Synthesis." Review of Educational Research 79 (4), 1391-1466.

Snowling, M., and Hulme, C. 2005. Learning to Read with Language Impairment. In The Science of Reading, edited by Snowling, M. J., and Hulme, C., 397-412. Malden: Blackwell.

Souvignier, E., and Antoniou, F. 2007. Förderung des Leseverständnisses bei Schülerinnen und Schülern mit Lernschwierigkeiten - eine Metaanalyse [Enhancing Reading Comprehension in Children With Learning Disabilities - a Meta-Analysis]. Vierteljahresschrift für Heilpädagogik und ihre Nachbargebiete 76: 46-62.

Stanovich, K. E. 1986. "Matthew Effects in Reading: Some Consequences of Individual Differences in the Acquisition of Literacy." Reading Research Quarterly 21: 36-407. Stephen, C., Ellis, J., and Martlew, J. 2010. "Taking active learning into the primary school: a matter of new practices?" Journal of Early Years Education 18 (4): 315-329.

Sternberg, R. J., and Powell, J. S. 1983. "Comprehending Verbal Comprehension". American Psychologist 38: 878-893.

Stobie, I., Boyle, J., Woolfson, L., Truswell, E., and Connaughton, N. 2004. “Quality indicators for effective early intervention in literacy and numeracy." Journal of Early Years Education 12 (2): 157-168.

Swanson, H. L. 1999. Interventions for Students With Learning Disabilities: A MetaAnalysis of Treatment Outcomes. New York: The Guilford Press.

Torgesen, J. K. 2005. Recent Discoveries on Remedial Interventions for Children With Dyslexia. In The Science of Reading, edited by Snowling, M. J., and Hulme, C., 521537. Malden: Blackwell.

Wigfield, A., Guthrie, J. T., Perencevich, K. C., Taboada, A., Klauda, S. L, McCrae, A., and Barbosa, P. 2008. "Role of Reading Engagement in Mediating Effects of Reading 
Comprehension Instruction on Reading Outcomes." Psychology in the Schools 45: 432445.

Yazici, Z., Genç İlter, B., and Glover, P. 2010. "How bilingual is bilingual? Mother-tongue proficiency and learning through a second language." Journal of Early Years Education 18 (3): 259-268. 


\section{Tables and Figures:}

Table 1. Comparison of gains in reading competencies of the LARS group receiving the programme (LARS) and the comparison group receiving traditional instruction (TI).

Table 2. Comparison of gains in spelling, linguistic and phonetically competencies of the LARS group receiving the programme (LARS) and the comparison group receiving traditional instruction $(\mathrm{TI})$.

Figure 1. Performance gain (t2-t1) in the abilities of reading in the LARS-group (LARS) receiving the programme and the comparison group receiving traditional instruction (TI), separate for children with German as mother language (L1) and German as a second language (L2).

Figure 2. Performance gain (t2-t1) in linguistic and spelling skills in the LARS-group (LARS) receiving the programme and the comparison group receiving traditional instruction (TI), separate for children with German as mother language (L1) and German as a second language (L2). 